\title{
Reutilização do óleo de fritura como uma alternativa de amenizar a poluição do solo
}

\author{
Reuse of frying oil as an alternative to mitigate pollution of soil
}

\author{
Daniela Alves da Costa ${ }^{1}$, Gilmeire Rulim Lopes ${ }^{1}$ e José Roberto Lopes² \\ ${ }^{1}$ Graduado (a), Instituto Federal de Educação, Ciência e Tecnologia de Mato Grosso - Campus São Vicente - Núcleo \\ Avançado de Jaciara, MT, Brasil. \\ ${ }^{2}$ Mestre em Desenvolvimento Local, Instituto Federal de Educação, Ciência e Tecnologia de Mato Grosso, MT, Brasil.
}

\section{Resumo}

Este é um trabalho realizado sobre o óleo vegetal utilizado nos domicílios para fritura, visando os princípios da Educação Ambiental e foi desenvolvido com o intuito de levar aos alunos da EJA (Educação de Jovens e Adultos), uma alternativa para amenizar parte dos impactos ao meio ambiente, causado por este resíduo quando descartado de forma inadequada. A partir dos dados obtidos através de pesquisas bibliográficas a respeito do consumo de óleo vegetal, surgiu a necessidade de sensibilizar a comunidade, sobre a reutilização de óleo vegetal utilizado nos domicílios para fritura. Aplicou-se uma intervenção na escola Municipal Magda Ivana na $1^{\circ}$ etapa do $2^{\circ}$ segmento da EJA noturno, em Jaciara-MT. Diante do objetivo proposto, de sensibilizar a respeito dos danos causados ao meio ambiente pelo uso e descarte inadequado de óleo vegetal, pôde-se concluir que o resultado esperado foi alcançado ao obter as respostas através de um questionário aplicado aos alunos para encerrar a intervenção pedagógica desenvolvida na escola.

Palavras-chave: Óleo vegetal. Educação Ambiental. Reutilização.

\begin{abstract}
This is a work on the vegetable oil used for frying in households, targeting the principles of Environmental Education and was developed with the intention of bringing students EJA (Youth and Adults), an alternative to mitigate the impacts to the environment environment caused by this waste when disposed of improperly. From the data obtained through literature searches on the consumption of vegetable oil, the need to sensitize the community on the reuse of vegetable oil used in households for frying. Applied intervention in school Municipal Magda Ivana in 1st stage of $2 n d$ segment of EJA night in Jaciara - MT. Given the stated objective of raising awareness about the damage caused to the environment by the use and improper disposal of vegetable oil, it could be concluded that the expected result was achieved to get the answers through a questionnaire administered to the students to end the educational intervention developed in school.
\end{abstract}




\section{Introdução}

Através da contextualização da Educação Ambiental, principalmente, nas escolas, pode-se inserir no cotidiano das pessoas a consciência necessária para contribuir com a preservação do meio ambiente. Neste trabalho serão abordadas algumas sugestões que podem contribuir significativamente para a conservação do mesmo e dos recursos naturais disponíveis.

Alternativas conscientes vêm sendo desenvolvidas ao longo dos anos, com isso, surge a necessidade de divulgar iniciativas para sensibilizar a população a respeito de medidas simples e práticas que podem ser adotada no cotidiano, como a reutilização do óleo vegetal utilizado nos domicílios para fritura, de modo que se possa reverter esse resíduo, que seria descartado muitas vezes de maneira inadequada, em matéria prima.

Reutilizar o óleo vegetal é uma atitude simples, porém, para a preservação do meio ambiente é uma grande alternativa de preservação. O óleo poderá ser reutilizado de várias maneiras, na fabricação de tintas, óleos para engrenagens, sabões, dentre outras, neste trabalho se destacará a reutilização do óleo vegetal para a fabricação do sabão artesanal.

Em uma visita na escola Municipal Magda Ivana, localizada no bairro Jardim Aeroporto, na cidade de Jaciara-MT, percebeu-se que a comunidade escolar é composta de pessoas simples e humilde e, em grande maioria, de baixa renda. Por esse motivo, os alunos da EJA noturno, que se trata de um público com idade superior a dezoito anos, surgiu a motivação de desenvolver este trabalho que trata da reutilização de óleo vegetal utilizado nos domicílios para fritura, e visa princípios de Educação Ambiental e da sensibilização para a preservação do meio ambiente, voltado para a realidade dos alunos daquela escola.

Além da principal alternativa sugerida, de reutilização do óleo vegetal para a fabricação de sabão líquido artesanal, será abordada também a alternativa de colaboração com projetos sociais que estão sendo desenvolvidos em pequenas e grandes cidades, iniciativas que parecem simples, porém, fazem grande diferença na preservação do meio ambiente.

O município de Jaciara-MT, manifestando sua preocupação com a preservação do meio ambiente, teve a iniciativa de recolher o óleo vegetal utilizado nos domicílios, juntamente com a população, que faz a doação dos restos de óleo vegetal, que após o seu uso não são mais reutilizados para consumo próprio, dando destinação correta a estes resíduos. Entretanto, após a intervenção na forma de uma palestra, que visa a Educação Ambiental, a resposta dos alunos surpreendeu, ainda de forma negativa.

\section{Fundamentação teórica}

\subsection{Contextualização da educação ambiental no processo ensino-aprendizagem}

Conforme KLAUCK (2010, citando Dias), quando se fala em desenvolvimento global em vários setores da sociedade como: tecnológico, produção e consumo, são processos que ocorrem de maneira desordenada causando grandes danos ao meio ambiente. Com esse quadro de degradação, ocorre a perda da qualidade de vida e muitos outros problemas aos seres vivos de modo geral.

Para complementar, CAVALCANTE (2002), diz que as maiores consequências dessa aceleração da produção, atingem diretamente o meio ambiente e a sociedade, que vivenciam 
os efeitos do uso desordenado dos recursos naturais. Uma consequência do consumo acelerado é a grande produção de lixo, que é um grande problema para o meio ambiente.

Uma forma de tentar conter essa degradação, segundo KLAUCK (2010, agora citando Carvalho), é fazer um alerta a respeito da Educação Ambiental podendo ser desenvolvido com a comunidade buscando conscientizar para a preservação e construção de um aprendizado para melhoria do meio ambiente, trazendo equilíbrio e harmonia entre o ser humano e a natureza.

A Educação Ambiental vem sendo inserida no contexto escolar de maneira significativa, KLAUCK (2010), diz que, o processo de Educação Ambiental deve ocorrer por meio da construção de valores sociais como: conhecimentos, habilidades, atitudes e competências, e devem ser voltadas para a conservação do meio ambiente, que é um bem de uso comum.

Conforme relata RUA et al (2010, citando Vaitsman) deve-se utilizar as situações de impactos ambientais no processo de ensino-aprendizagem de forma dinâmica, e fazer com que os professores utilizem em sua prática pedagógica conteúdos para despertar nos alunos a consciência da importância do estudo de ciências, que contribuirá em um processo de construção de conceitos significativos e melhoria de vida, independente da situação socioeconômica.

Portanto, quando os alunos se deparam com situações que se aproximam de sua realidade, poderão assimilar o conteúdo trabalhado pelos professores em sala de aula, ao que estão vivenciando, dessa forma estarão utilizando os conhecimentos adquiridos na sua prática diária e construindo suas próprias idéias através do processo ensino-aprendizagem, assim fazem uma relação do conteúdo com o que já "sabiam", porém, ainda não era posto em prática.

Segundo CAVALCANTE (2002), para que isso aconteça é preciso despertar a consciência ambiental dos alunos, quanto à necessidade do desenvolvimento da cidadania de forma sustentável, mediante a transformação da escola que apenas transmite a informação, para a escola que forma cidadãos comprometidos com o meio ambiente.

Segundo LOPES (2009, citando Reigota), é por meio da Educação Ambiental em seus vários níveis sociais, intelectuais, técnicos e científicos que pode se atingir, através da conscientização e sensibilização, a meta do desenvolvimento sustentável, assim pode-se oferecer condições para que as gerações futuras tenham recursos naturais suficientes para sobreviver em harmonia com o meio ambiente.

Nesse sentido, pode-se afirmar que a atuação individual do ser humano será somada as ações coletivas na busca de possíveis soluções para os problemas ambientais e sociais que são mais frequentes a cada dia, tendo em vista que após a sensibilização conscientemente poderá ser percebidas as consequências da degradação ambiental.

No município de Jaciara-MT, a Secretaria Adjunta de Meio Ambiente vem desenvolvendo ações de sensibilização para a comunidade, alertando sobre as consequências do mau uso dos recursos naturais. A idéia dessas iniciativas é conscientizar as pessoas para que com pequenas ações algo de importante seja feito para a natureza.

A secretária adjunta de Meio Ambiente, Cenita Oliveira, relata que é necessário sensibilizar a população para que todos possam desenvolver ações que colaborem com o meio ambiente, porque ele é um patrimônio e deve-se deixar esse patrimônio limpo e bonito para que outras pessoas possam também desfrutar seus benefícios.

Algumas atividades são desenvolvidas nas escolas no sentido de alertar para a preservação do meio ambiente. O Projeto Político Pedagógico da Escola Magda Ivana, 
propõe que a Educação Ambiental e a orientação para o trabalho deverão ser contempladas nas várias áreas do conhecimento e uma forma de abordar esses assuntos é a utilização dos temas geradores.

Através dos temas geradores adotados pela escola, a equipe pedagógica poderá elaborar projetos que poderão ser desenvolvidos ao longo do ano envolvendo alunos e professores, o que estimula a fixação dos conteúdos trabalhados em sala de aula. Ao aplicar os conteúdos, estes deverão envolver um tema comum, que se trata de um assunto em destaque no município, região e/ou comunidade.

Está em desenvolvimento no município de Jaciara-MT, através da secretaria adjunta de meio ambiente, um projeto que recolhe lixo eletrônico, o qual não pode ser descartado juntamente com o lixo comum. Este projeto, também recolhe óleo vegetal utilizado nos domicílios para fritura, para dar destinação correta a esse resíduo, evitando que seja descartado de maneira inadequada, prevenindo os danos ao meio ambiente.

\subsection{Reutilização de óleo vegetal: uma alternativa consciente}

O consumo de óleo vegetal é muito alto no Brasil, com base no que afirma Martins (2010, citando Humberto), os brasileiros consomem aproximadamente três bilhões de litros de óleo de fritura por ano. Em algumas regiões o consumo se destaca pela grande quantidade consumida, como é o caso do Espírito Santo, em que o consumo chega a aproximadamente 150 milhões de litros de óleo vegetal por ano, devido a cultura culinária da região.

Segundo a Legislação Ambiental, o tema "óleo de cozinha" está sendo abordado pelo projeto de Lei no 2.074 de 19 de setembro de 2007 em tramitação no Congresso Federal Brasileiro, em diversas discussões para tratar do destino deste resíduo que vem causando grandes danos ambientais, quando descartado de forma inadequada pelos lares, microempresários do ramo de salgadinhos fritos, lanchonetes e restaurantes, entre outros.

Com o passar do tempo, grande quantidade de restos de óleo vegetal usado em frituras seriam despejados nas pias de cozinha, nas águas de riachos e rios, gerando a contaminação da fauna aquática, do solo e a impermeabilidade do mesmo, além de provocar a danificação das tubulações domésticas e das redes de tratamento de esgoto.

Diz ainda Lopes (2009) que o óleo de cozinha quando é jogado diretamente na pia pode causar sérios prejuízos ao meio ambiente, se o produto for descartado nas redes de esgoto poderá encarecer o tratamento dos resíduos em até $45 \%$ e o que permanece nos rios poderá provocar a impermeabilização dos leitos e do solo, isso contribui para que ocorram as enchentes.

Uma das soluções para este problema é a reutilização do óleo vegetal, que poderá acontecer de várias maneiras, como por exemplo, a fabricação de sabão líquido artesanal e a conscientização a respeito dos danos que causa o descarte inadequado deste resíduo, assim esse produto será reaproveitado sem dar prejuízos ao meio ambiente.

Conforme GODOY et al (2010, citando Pitta Junior), o desperdício do óleo de cozinha pode e deve voltar em forma de benefícios trazendo vantagens competitivas e econômicas, evitando grandes problemas ambientais e servindo de matéria prima na fabricação de diversos produtos, tais como sabões líquido e em barra, detergentes, tintas, óleos para engrenagens e etc.

Sendo assim, no momento em que milhares de famílias obtiverem orientações adequadas sobre a reutilização do óleo de cozinha que muitas vezes descartam de modo 
inadequado, conseguirão gerar renda e dar a destinação correta ao resto de óleo de fritura que acabariam com o descarte inadequado.

Dentre muitas outras maneiras de reutilização do óleo vegetal utilizado nos domicílios para fritura, este trabalho mostrará a importância da reutilização deste resíduo como uma forma alternativa de amenizar a poluição do solo, e poderá ser deixada a sugestão da fabricação de sabão líquido artesanal e a colaboração com projetos sociais que reutilizam o óleo vegetal, envolvendo alunos e professores.

Além da sugestão de reutilização do óleo vegetal, sugere-se que o armazenamento do sabão líquido artesanal, seja feito em garrafas plásticas (de amaciante de roupas e/ou água sanitária), que se trata de material de difícil decomposição no meio ambiente, pois os plásticos utilizados na fabricação dessas garrafas demoram muitos anos para se decompor na natureza. Segundo COSTA (2010) o tempo de decomposição das garrafas de vidro e plástico, ainda é indeterminado.

Sabe-se que as garrafas plásticas, além se serem reutilizadas, também poderão ser recicladas por indústrias especializadas nas grandes metrópoles, podendo voltar na forma de novas garrafas ou outros produtos, que utilizam esse tipo de resíduo como matéria prima.

No município de Jaciara-MT não há locais onde se recicle esse tipo de material, mas existem pontos de coleta, onde alguns catadores fazem a separação dessas garrafas e outros materiais recicláveis (latas de alumínio, papelão, plásticos, etc.), que serão enviadas para as fábricas de reciclagem.

O Brasil ainda tem 4 mil lixões apenas $30 \%$ a $40 \%$ do lixo total coletado no país são dispostos em aterros sanitários adequados. Além disso, a reciclagem é muito baixa no Brasil, segundo avalia o secretário da Associação Brasileira de Resíduos Sólidos e Limpeza Pública (ABLP), Antonio Simões Garcia. Ele informou que os serviços de aproveitamento de material descartado não transformam no país sequer $2 \%$ do volume que pode ser reciclado. GRANDA (2012)

Inicialmente a coleta seria feita por meio da empresa "Recoleo", cuja Matriz fica em Belo Horizonte-MG e a filial mais próxima em São José do Povo-MT, porém, a empresa não desenvolveu a coleta da forma como foi proposta a princípio. Diante dessa situação, a Secretária Adjunta de Meio Ambiente, Cenita Maria Oliveira, segundo seu relato, interessouse em implantar, em parceria com as escolas, a efetivação da coleta do óleo vegetal.

Segundo a bióloga Lucimara Afonso Castilho e Cenita Maria Oliveira, a secretaria pretende realizar uma parceria com as escolas municipais, estaduais e particulares do município de Jaciara-MT, visando otimizar os resultados do projeto: “Reciclagem de óleo de cozinha usado".

Com a colaboração dos profissionais da educação pretende-se sensibilizar a comunidade escolar a respeito dos problemas ambientais causados pelo descarte inadequado do óleo vegetal e conquistar a participação dela no sentido de armazenar o óleo em garrafas PET e entregá-lo para ser reutilizado.

Os pontos de coleta voluntária serão instalados nas escolas e não mais nos supermercados, onde foram instalados inicialmente. Nas escolas poderão ser desenvolvidos momentos de incentivo com os alunos para que ocorra a participação efetiva deles na coleta do óleo vegetal e devido à dinâmica de sensibilização ser mais propícia no ambiente escolar. 


\section{Materiais e métodos}

Para o desenvolvimento deste trabalho, foram feitas pesquisas bibliográficas, analisando artigos, livros e as diversas fontes de informações disponíveis para o estudo do tema óleo vegetal utilizado nos domicílios para fritura, foi aplicado uma intervenção com o intuito de contribuir com a conscientização e sensibilização dos alunos, professores e profissionais da Escola Municipal Magda Ivana.

Após as pesquisas bibliográficas, iniciaram-se as reuniões nas quais foram feitas a preparação para a realização da intervenção e elaboração do questionário para coleta de dados. A intervenção ocorreu através de aula expositiva e a coleta dos dados mediante a aplicação de um questionário na turma da $1^{\underline{a}}$ etapa do $2^{\underline{0}}$ segmento da EJA.

A aula expositiva foi realizada na Escola Municipal Magda Ivana no dia 30/08/2013, com o uso do data show para apresentar slides de fotos de locais do município de Jaciara-MT que estão poluídos. Através dessas imagens iniciou-se um debate a respeito da poluição, em que os alunos puderam se manifestar dando sua opinião, de maneira geral e principalmente sobre o tema óleo vegetal e os danos que causam o seu descarte diretamente na natureza.

Pode-se deixar a sugestão da fabricação de sabão, através da distribuição de uma receita de sabão liquido aos participantes da intervenção pedagógica. Dentre vários roteiros existentes, ofereceu-se uma alternativa de sabão líquido, que segue abaixo:

Ingredientes:

a) 70 litros de água;

b) 4 litros de óleo utilizado em frituras;

c) 2 litros de álcool;

d) $1 \mathrm{~kg}$ de soda caustica $(\mathrm{NaOH})$;

e) Essência de sua preferência (opcional);

Neste trabalho poderá ser utilizado o óleo de fritura (óleo de vegetal) obtido por meio da coleta realizada pelos próprios alunos. Quanto ao preparo do sabão, sugeriu-se que os participantes que realizassem essa prática deveriam atentar-se para o uso dos EPI's (Equipamento de Proteção Individual), necessários para o manuseio, tais como: luvas, máscara; juntamente com os equipamentos necessários para o preparo do sabão sem o contato direto com os reagentes, uma vez que serão utilizados alguns produtos tóxicos, que não devem, em hipótese alguma, serem manipulados por crianças ou por pessoas que não possuem os conhecimentos prévios.

Sugeriu-se que para o preparo do sabão fossem realizados os passos, que seguiram juntamente com o roteiro distribuída aos participantes da intervenção, descritos a seguir:

1) Dissolver a soda em 4 litros de água, agitando até que toda a soda cáustica seja dissolvida totalmente;

2) Colocar dois litros de álcool, devagar para evitar acidentes;

3) Colocar 4 litros de óleo, também devagar;

4) Bater até formar uma nata branca por cima;

5) Acrescentar 4 litros de água quente;

6) Acrescentar o restante de água, de modo que complete os 70 litros;

7) Mexer em todas as etapas sem parar;

8) Após o produto pronto, engarrafar e manter em local arejado e fora do alcance de crianças.

Logo depois, aplicou-se um questionário, contendo seis perguntas relacionadas ao tema óleo vegetal, para se obter dados que dariam suporte no desenvolvimento deste 
trabalho. Para melhor compreensão dos alunos, a professora de ciências, regente da turma da $1^{\underline{a}}$ etapa do $2^{\underline{o}}$ segmento da EJA, aplicou o questionário no dia 05/09/2013 e juntamente com os alunos fizeram a leitura das perguntas. O questionário foi aplicado em data diferente à data da intervenção devido ao tempo que foi insuficiente para a realização desta atividade na mesma data, essa diferença, entretanto não prejudicou em nenhum aspecto $o$ desenvolvimento do trabalho e a coleta dos dados.

\section{Resultados e discussões}

A partir das respostas obtidas por meio da pergunta que se refere ao consumo do óleo vegetal (óleo de cozinha) nos domicílios, os dados obtidos, foram suficientes para constatar que, de fato, o consumo de óleo vegetal é bastante alto, como pode ser observado na Figura 1. Por esse motivo é que se observou a necessidade de fazer essa conscientização a respeito da reutilização e consumo do óleo vegetal através dos princípios de Educação Ambiental.

Para que isso ocorra, é necessário desenvolver projetos e mobilizações, através dos princípios da Educação Ambiental envolvendo alunos, professores bem como toda a comunidade escolar. Este trabalho tem como principal objetivo a sensibilização a respeito do consumo e reutilização do óleo vegetal utilizado nos domicílios para fritura (Figura 1).

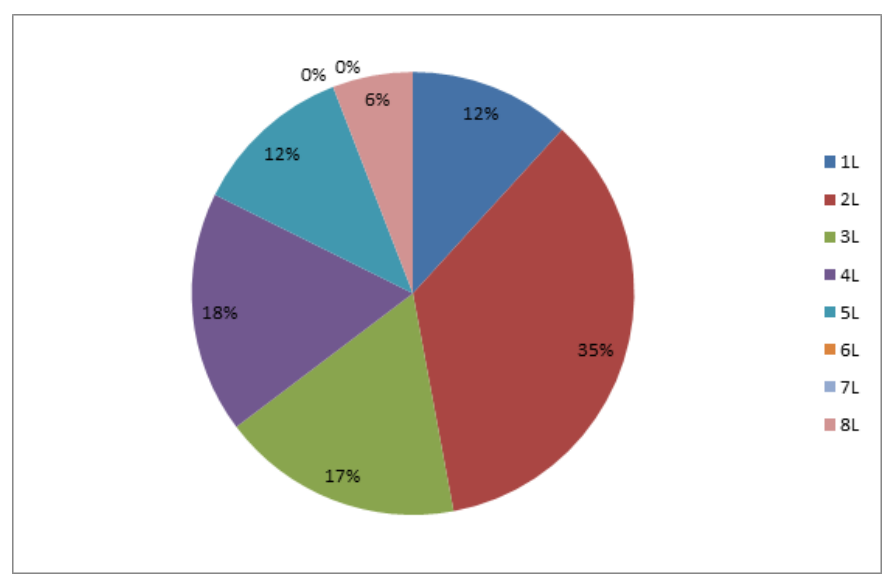

Figura 1 - Consumo mensal de óleo vegetal

Sobre o número de pessoas que ainda não reutilizam o óleo vegetal, $53 \%$ dos participantes da intervenção, talvez por falta de conhecimento a respeito dos problemas que causam o descarte inadequado deste resíduo, ainda não o reutiliza, conforme mostra a figura 2, assim contribui-se com sugestões alternativas para reutilizar este resíduo.

$\mathrm{Na}$ realização desse projeto, além de contar com experiência que os alunos já possuem, foram sugeridas algumas maneiras de reutilização do óleo vegetal como: a fabricação de sabão líquido artesanal e a divulgação de projetos que reutilizam o óleo vegetal em parceria com a sociedade, para que todos possam contribuir de maneira adequada com o meio ambiente de forma consciente.

O trabalho realizado teve, também, o intuito de sensibilizar a comunidade através de uma intervenção onde se falou da prática de sabão líquido artesanal, realizada na Escola 
Municipal Magda Ivana juntamente com os alunos da EJA (noturno) e os demais profissionais da educação presentes naquele momento na escola (Figura 2).

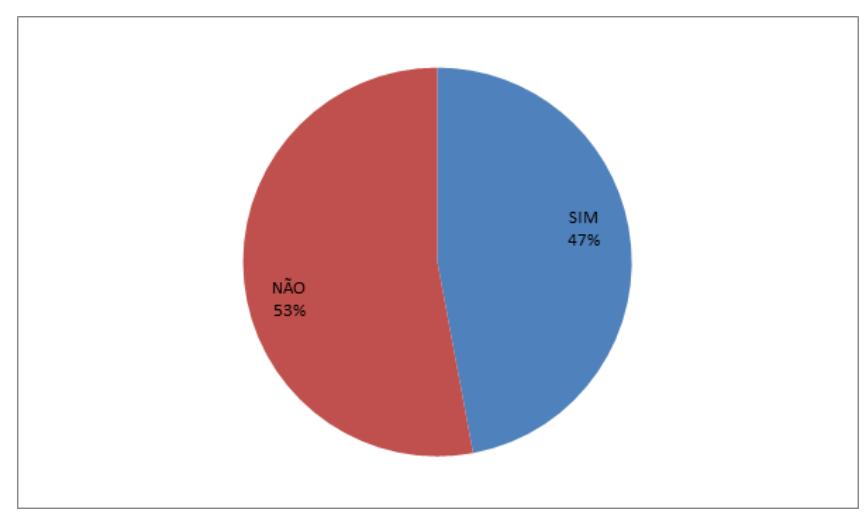

Figura 2 - Reutilização do óleo vegetal

Os participantes quando foram questionados a respeito das formas como reutilizam o óleo vegetal em seus domicílios, $47 \%$ relatou que já reutilizavam este resíduo para a fabricação do sabão artesanal e este é utilizado para consumo próprio.

De acordo com a Figura 3, observa-se que grande maioria dos participantes reutilizam o óleo vegetal, de acordo com o principal objetivo proposto pelo projeto, a fabricação de sabão artesanal, ou seja, já tem informações a respeito do tema tratado na intervenção. Deixou-se também como sugestão a doação do óleo vegetal para projetos sociais, de modo que não seja depositado em local inadequado.

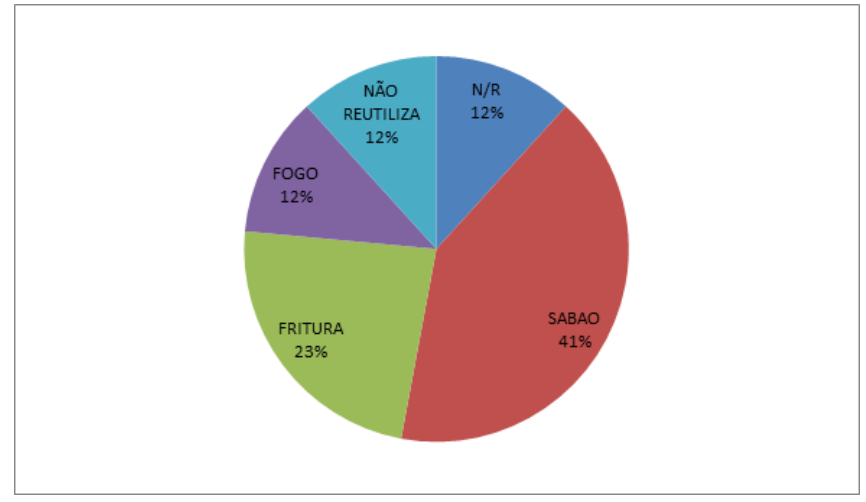

Figura 3 - Como ocorre a reutilização do óleo vegetal

Dentre muitas outras maneiras de reutilização do óleo vegetal utilizado nos domicílios para fritura, o objetivo principal é mostrar a reutilização deste resíduo como uma forma alternativa de amenizar a poluição do solo, para que isso ocorra, deve-se valorizar os princípios da Educação Ambiental no sentido de oferecer sugestões que possam contribuir com o meio ambiente.

Na Figura 4 podemos observar os resultados das respostas do questionamento sobre as alternativas que os participantes da intervenção já conhecem para reutilizar o óleo vegetal, verifica-se que a grande maioria dos participantes já trazem conhecimentos prévios de uma 
das alternativas, sugerida e adequada de reutilizar o óleo vegetal de cozinha, novamente a fabricação do sabão artesanal teve o maior percentual das respostas, totalizando $53 \%$.

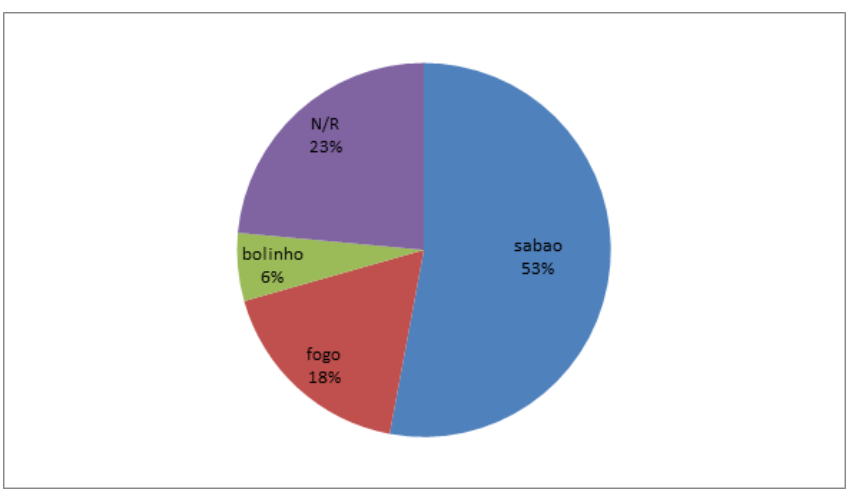

Figura 4 - Outras formas de reutilização do óleo vegetal

Os participantes da intervenção, quando questionados a respeito dos benefícios que a reutilização do óleo vegetal pode trazer para o meio ambiente, responderam que está prática contribui com a preservação dos rios, do solo, ou seja, do meio ambiente de uma maneira geral.

Portanto, pode-se concluir que os participantes da intervenção saíram sensibilizados a respeito dos danos que o óleo vegetal pode causar ao meio ambiente quando descartados de forma inadequada. Com as respostas representadas na Figura 5, observa-se que a ação realizada com o objetivo de sensibilização os participantes teve bom resultado.

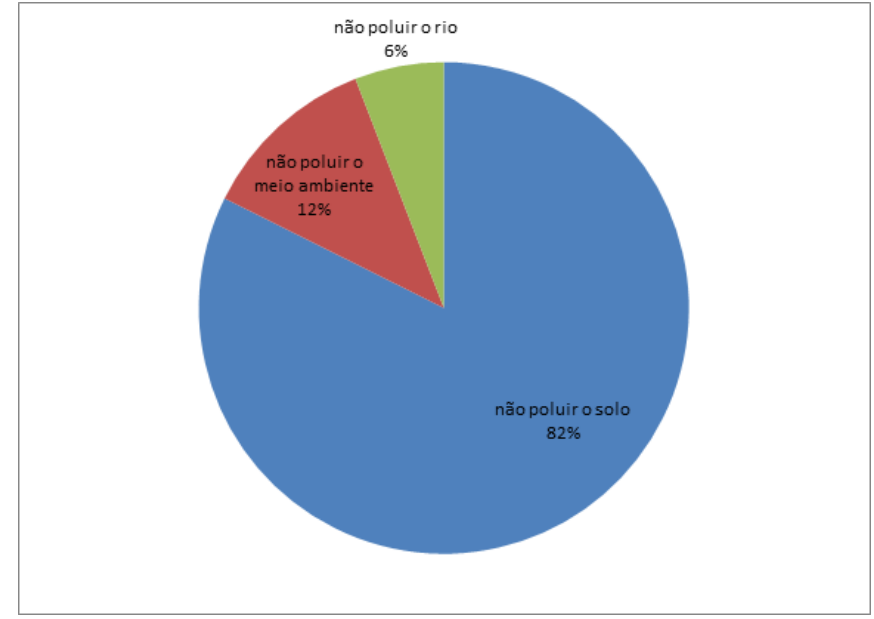

Figura 5 -. Benefícios da reutilização do óleo vegetal

Apesar de existirem muitos projetos de preservação ambiental, não somente de reutilização de óleo vegetal, a divulgação desses projetos ainda é falha, não atinge todos os públicos. Em Jaciara, está em desenvolvimento um projeto que recolhe o óleo vegetal utilizado nos domicílios para fritura, para que seja reutilizado de modo a não ser descartado de maneira inadequada.

Diante dessa situação surgiu à necessidade de contribuir com essa divulgação, foi realizada a divulgação desse projeto através da disponibilização dos pontos de coleta do óleo vegetal a ser reutilizado e os nomes dos responsáveis por cada ponto. Dessa maneira, esperase contribuir com o desenvolvimento do projeto e com a sensibilização dos envolvidos na 
atividade realizada na escola Municipal Magda Ivana, com os alunos e professores da EJA noturno.

Ainda que tenha ocorrido a divulgação desse projeto, observa-se na Figura 6, que os participantes da intervenção ainda responderam de maneira negativa, quando questionados se conhecem algum projeto social que reutiliza o óleo vegetal para a fabricação de produtos derivados deste resíduo.

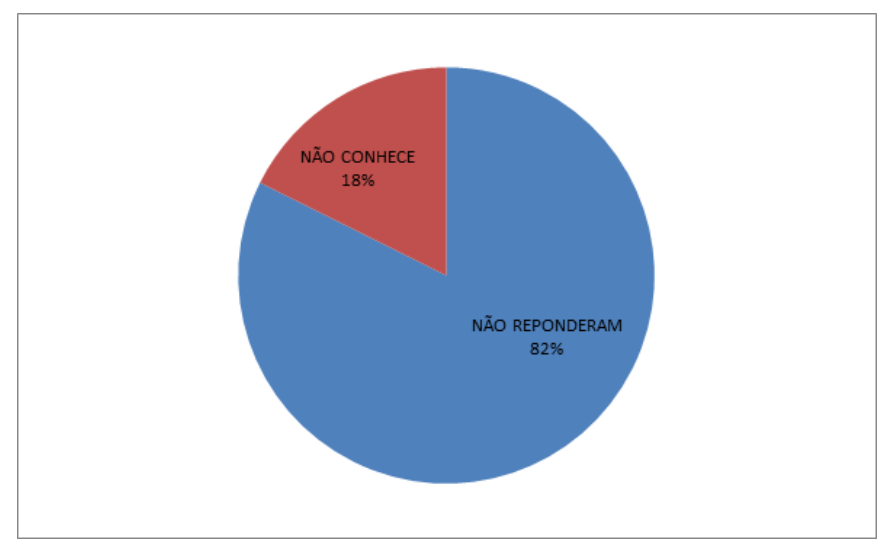

Figura 6 - Projetos sociais que reutiliza óleo vegetal

Diante dos resultados apresentados, pode-se observar que através de iniciativas, mesmo que pequenas, mas que podem fazer a diferença para o meio ambiente, é que a população será sensibilizada. Através da divulgação de projetos que contribuem com a preservação ambiental e de iniciativas de pequenos projetos, como é o caso deste trabalho que sugere por meio da Educação Ambiental.

A Educação Ambiental é um processo permanente no qual os indivíduos e a comunidade tomam consciência do seu meio ambiente e adquirem conhecimentos, valores, habilidades, experiências e determinação que os tornem aptos a agir e resolver problemas ambientais, presentes e futuros. (RUA, SOUZA, 2010).

\section{Considerações finais}

De acordo com os resultados obtidos durante a intervenção que grande parte dos objetivos foram alcançados no que diz respeito à interação e contribuição dos alunos e professores, que desempenharam um papel importante no processo ensino-aprendizagem e engrandeceram o conhecimento na realização deste projeto, despertando o interesse para novas descobertas.

Entretanto, a surpresa maior foi constatar que apesar dos alunos da EJA terem recebido informações a respeito do projeto realizado pela Secretaria Adjunta de Meio Ambiente, ainda responderam de maneira negativa quando questionados sobre projetos sociais que reutilizam óleo vegetal no município de Jaciara-MT.

Mas a percepção que terão, fará a diferença na construção de um pensamento holístico, ou seja, terão um olhar mais atento e com mais cuidado sobre a questão da reutilização do óleo vegetal, na preservação do meio ambiente, tornarão imprescindível pequenas atitudes de ajuda e colaboração. 
Deixou-se como sugestão a reutilização do óleo vegetal na realização prática da fabricação do sabão artesanal, no momento da intervenção, para que fique ainda mais claro como pode ocorrer à reutilização do óleo vegetal de maneira fácil como uma forma alternativa de amenizar a poluição do solo. Entende-se, então, que só assim será possível melhorar a conservação e a qualidade da vida na terra.

\section{Agradecimentos}

À Coordenação de Aperfeiçoamento de Pessoal de Nível Superior (CAPES) pelo subsídio através do Programa de Consolidação das Licenciaturas (PRODOCENCIA) Edital 019/2013, processo № 113.657, e do Programa Institucional de Bolsa de Iniciação à Docência (PIBID) Edital № 061/2013, processo № 128.570, IFMT/Campus São Vicente/Sub Projeto Ciências.

\section{Referências}

CAVALCANTE, M. B. Educação Ambiental: da escola a comunidade. Io Congresso Brasileiro de Extensão Universitária, João Pessoa/PB, em 2002.

COSTA, M. P. Reciclando o lixo, reciclando a vida: uma experiência exitosa através da produção de vídeos. V EPEAL, Pesquisa em Educação: Desenvolvimento, Ética e Responsabilidade Social, Maceió/AL, 2010.

GODOY, P. O.; OLISKOVICZ, K.; BERNARDINO, V. M.; CHAVES, W. R.; PIVA, C. D.; RIGO, A. S. N. Consciência limpa: Reciclando o óleo de cozinha. Anuário da Produção de Iniciação Científica Discente, v.13, n.17, p.205-217, 2010.

KLAUCK, C. R. EDUCAÇÃO AMBIENTAL: Um elo entre conhecimento cientifico e comunidade, Revista Conhecimento Online, ano 1, v. 2, março 2010.

LOPES, R. C.; BALDIN, N. Educação ambiental para a reutilização do óleo de cozinha na produção de sabão - projeto "Ecolimpo". In: Anais do IX Congresso Nacional de Educação (EDUCERE) - III Encontro Sul Brasileiro de Psicopedagogia. Paraná: PUC, 2009.

PREFEITURA MUNICIPAL DE JACIARA/MT. Secretaria de Educação, Cultura e Desporto de Jaciara. Projeto Político Pedagógico da Escola Municipal Magda Ivana, Reformulado em 2012.

RUA, E. R.; SOUZA, P. S. A. Educação Ambiental em uma Abordagem Interdisciplinar e Contextualizada por meio das Disciplinas Química e Estudos Regionais. Revista Química Nova Na Escola, v.32, n.2, p.95-100, 2010. 